\title{
Drought in forest understory ecosystems - a novel rainfall reduction experiment
}

\author{
K. F. Gimbel ${ }^{1}$, K. Felsmann ${ }^{2}$, M. Baudis ${ }^{3}$, H. Puhlmann ${ }^{5}$, A. Gessler ${ }^{2,6,7}$, H. Bruelheide ${ }^{3,4}$, Z. Kayler ${ }^{2}$, \\ R. H. Ellerbrock ${ }^{2}$, A. Ulrich ${ }^{2}$, E. Welk ${ }^{3,4}$, and M. Weiler ${ }^{1}$ \\ ${ }^{1}$ Chair of Hydrology, Faculty of Environment and Natural Resources, University of Freiburg, Freiburg, Germany \\ ${ }^{2}$ Institute for Landscape Biogeochemistry, Leibniz Center for Agricultural Landscape Research e.V. (ZALF), \\ Leipniz, Germany \\ ${ }^{3}$ Institute of Biology, Geobotany and Botanical Garden, Martin Luther University Halle-Wittenberg, Germany \\ ${ }^{4}$ German Centre for Integrative Biodiversity Research (iDiv) Leipzig, Germany \\ ${ }^{5}$ Forest Research Institute Baden-Württemberg, Freiburg, Germany \\ ${ }^{6}$ Research Unit Forest dynamics, Swiss Federal Research Institute for Forest, Snow and Landscape Research WSL, \\ Zürchestr. 111, 8903 Birmensdorf, Switzerland \\ ${ }^{7}$ Berlin-Brandenburg Institute of Advanced Biodiversity Research (BBIB), 14195 Berlin, Germany
}

Correspondence to: K. F. Gimbel (katharina.gimbel@hydrology.uni-freiburg.de)

Received: 16 June 2014 - Published in Biogeosciences Discuss.: 7 October 2014

Revised: 19 January 2015 - Accepted: 20 January 2015 - Published: 17 February 2015

\begin{abstract}
Precipitation patterns across Central Europe are expected to change over the 21 st century due to climate change. This may reduce water availability during the plantgrowing season and hence affect the performance and vitality of forest ecosystems. We established a novel rainfall reduction experiment on nine sites in Germany to investigate drought effects on soil-forest-understory ecosystems. A realistic, but extreme annual drought with a return period of 40 years, which corresponds to the $2.5 \%$ percentile of the annual precipitation, was imposed. At all sites, we were able to reach the target values of rainfall reduction, while other important ecosystem variables like air temperature, humidity, and soil temperature remained unaffected due to the novel design of a flexible roof. The first year of drought showed considerable changes in the soil moisture dynamics relative to the control sites, which affected leaf stomatal conductance of understory species as well as evapotranspiration rates of the forest understory.
\end{abstract}

\section{Introduction}

Temperature and precipitation are two of the key drivers of ecosystem processes. Climate change alters global meteorological processes such as atmospheric circulation and precipitation (Seneviratne et al., 2006; IPCC, 2012). In Central Europe, climate change is predicted to severely affect precipitation patterns, which will result in reduced precipitation input during the vegetation periods (Prudhomme et al., 2014; IPCC, 2012; Christensen and Christensen, 2007). Field experiments are a valuable tool to examine the consequences of changing climate on ecosystem processes, as demonstrated in numerous studies, and thus, a number of climate change experiments have been established around the world in various ecosystems: e.g., dry heathland ecosystems in Denmark (Albert et al., 2011; Selsted et al., 2012), Amazonian rainforest Brazil (da Costa et al., 2011), temperate mixed broad-leaved forest (Schraml and Rennenberg, 2002) and sub-Mediterranean forest (Rodriguez-Calcerrada et al., 2009).

Forests in Central Europe are different from most other terrestrial ecosystems in the world; while forest trees and the canopy are managed, the forest understory is a relatively natural system, which is, however, influenced by the over- 
story (Ampoorter et al., 2014). The forest understory contains a great variety of the biodiversity in forests (Gillam, 2007), especially in Central Europe with its comparably low tree diversity. Whereas the effects of drought on grasslands have been addressed intensively there are only few studies examining the effect of climate change on the understory of forests (Ozolincus et al., 2009). It remains unclear how the forest understory will respond to continuously reduced precipitation, as might be the case in a future Europe under climate change (Kreuzwieser and Gessler, 2010). In general, we can expect both direct and indirect impacts of continuously reduced precipitation on the forest-understory system. Decreased transpiration and water potentials are short-term responses of plants to drought (Tschaplinski et al., 1998). As a result of the drop in water potential, stomatal closure will occur, limiting water fluxes at the cost of reduced $\mathrm{CO}_{2}$ uptake and assimilation. At the level of plant communities and long-term response, the stress induced by drought may modify competition and facilitation, or it may tip the balance towards a state where only stress-resistant plant species are able to survive (McDowell et al., 2008).

Since plants are closely linked to soil physical properties and interacting with soil microbiota, the response of plants to drought should be coordinated with detailed characterization of soil and hydrological properties. Soil characteristics are closely linked to the activity of soil microbiota and plant roots, which modify water flow pathways along roots, organic matter and water repellency of soils (Birkhofer et al., 2012; Carminati et al., 2011; Gregory, 2006; Schaumann et al., 2007; Spohn and Rillig, 2012; Tang et al., 2011; Tisdall and Oades, 1982). Through shrinkage and fracturing of soil aggregates, soil structure is also responding to changing environmental conditions (in particular drought). Hence, the understory vegetation will be also be affected by indirect drought effects driven by soil processes. Since plants are closely linked to soil physical properties and interact with soil microbiota, the response of plants to drought should not be studied isolated.

Our current understanding of drought effects on the forest understory is ambiguous and insufficient for predicting responses of the forest ecosystem: on one hand, the understory remains largely unmanaged, while the overstory structure of trees and canopy is a consequence of forest management practices. But on the other hand, the understory also harbors the tree seedlings, which will form the next tree generation and thus we need a better mechanistic comprehension of this system. The knowledge of such mechanisms related to the understory response to drought need to be included in current forest growth models in order to understand all aspects of the system - including natural regeneration - under climate change.

We thus propose to experimentally manipulate precipitation and investigate in detail the consequences for soil moisture, soil hydrological functions, and water uptake as well as vegetation structure, but also including more in-depth studies

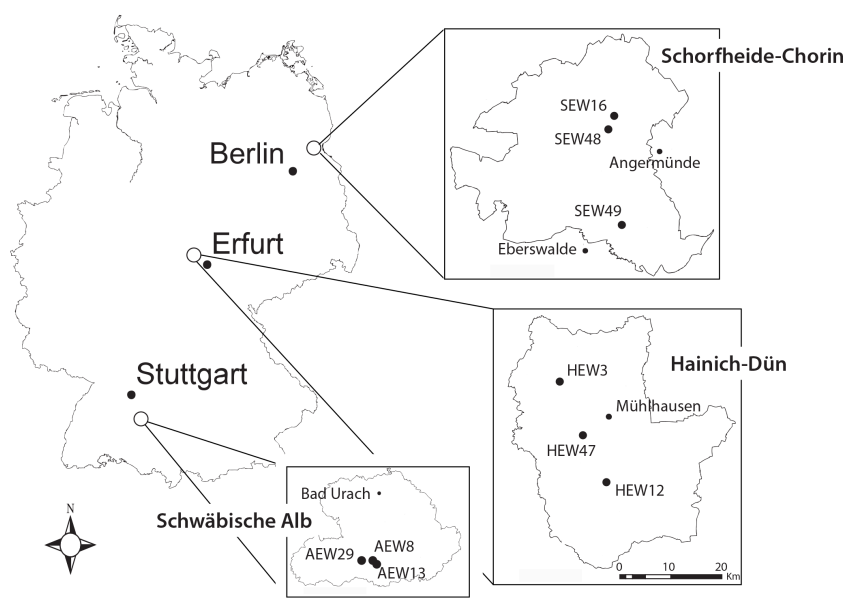

Figure 1. Location of the three Biodiversity Exploratories and the experimental plots.

such as assessments of the microbial community structure. The aim of this study was to apply a realistic reduction of precipitation whilst avoiding any associated effects on air temperature or humidity and to observe the initial drought effects on the forest-understory-soil system. Many other precipitation manipulation experiments introduce extreme short-time drought events (e.g., Glaser et al., 2013), which often eliminate precipitation completely, generating unrealistic drought effects (Beier et al., 2012). In addition, the constructions used in previous studies often need electrical supply or intensive technical installation, supervision, and maintenance (e.g., Beier et al., 2004; Albert et al., 2011; Parra et al., 2012; Kopittke et al., 2014). Our approach employs a moderate, adaptive, and continuous rainfall reduction, equivalent to a drought with 40 -year return period. To achieve our goal, nine investigation sites at three different geographical locations in Germany were established. Here, we describe and explain the set up and monitoring of the rainfall exclusion experiment and present the first results of rainfall reduction with soil physical and biological evidence on the effectiveness of the drought set up.

\section{Material and methods}

\subsection{Investigation sites}

Our study sites are part of the German Biodiversity Exploratories, which are located in three different sites in Germany (Schwäbische Alb, Hainich-Dün, Schorfheide-Chorin; Fig. 1). The German Biodiversity Exploratories comprise a research platform for biodiversity and ecosystem research (DFG Priority Programm 1374). The research focus of the Biodiversity Exploratories is on understanding the interrelationship between land use, biodiversity and multiple ecosystem processes, as well as biodiversity change and bio- 
Table 1. Forest type, main tree species, tree stand density and understory community at the various experimental plots.

\begin{tabular}{|c|c|c|c|c|c|}
\hline Exploratory & Plot name & Forest type & $\begin{array}{l}\text { Main tree } \\
\text { species } \\
\left(\mathrm{m}^{2} \mathrm{ha}^{-1}\right)\end{array}$ & $\begin{array}{l}\text { Tree } \\
\text { basal area }\end{array}$ & Plant community \\
\hline \multirow[t]{3}{*}{ Schwäbische Alb } & AEW8 & Unmanaged & Beech & 39.04 & Hordelymo-Fagetum \\
\hline & AEW13 & Intensively managed & Spruce & 38.08 & Picea abies plantation \\
\hline & AEW29 & Managed & Beech & 31.59 & Hordelymo-Fagetum \\
\hline \multirow[t]{3}{*}{ Hainich-Dün } & HEW3 & Intensively managed & Spruce & 27.77 & Picea abies plantation \\
\hline & HEW12 & Unmanaged & Beech & 32.15 & Hordelymo-Fagetum \\
\hline & HEW47 & Managed & Beech & 34.55 & Hordelymo-Fagetum \\
\hline \multirow[t]{3}{*}{ Schorfheide-Chorin } & SEW16 & Intensively managed & Pine & 37.92 & $\begin{array}{l}\text { Deschampsia-flexuosa- } \\
\text { Pinus-sylvestris community }\end{array}$ \\
\hline & SEW48 & Unmanaged & Beech & 25.95 & Galio-Fagetum \\
\hline & SEW49 & Managed & Beech & 36.11 & Galio-Fagetum \\
\hline
\end{tabular}

geochemical cycles in real-world ecosystems (Fischer et al., 2010). In each of the Exploratories, we selected three forest plots, which cover different forest types, management intensities, and understory vegetation communities (Table 1), but are similar with respect to topography and soil type within each exploratory.

The site of the Biodiversity Exploratory Schwäbische Alb is located in the low mountain ranges of southwestern Germany; the underlying geology consists of Jurassic shell limestone. The soils at the investigation sites are extremely rich in clay, are very shallow ( 25 to $35 \mathrm{~cm}$ ) and have a very high stone content. The soils of the Hainich-Dün site (situated in central Germany) generally have a loamy to clayey texture with soil depths between 45 and $65 \mathrm{~cm}$ and low water conductivity. Here, the underlying geology consists of Triassic limestone.

The site of the Biodiversity Exploratory SchorfheideChorin is located in a young glacial landscape in the lowlands of northeastern Germany. The dominant geological substrate is glacial till covered by glacio-fluvial or aeolian sands. Therefore, soils have textures in the range of sandy loam to pure sand. Due to their sandy texture, the soil depth in this area is identified by rooting depths.

More information on general plot properties is prepared in Table 2. All weather data is taken from stations of the German weather service (DWD, actual and annual data years 1950-2010) nearby (station IDs 03402, 00487, and 00164).

\subsection{Roof construction for a flexible rainfall reduction}

At each of the nine selected plots, five roof subplots and five control subplots were instrumented. One of the five roof subplots and one of the five control subplots has a size of $10 \times 10 \mathrm{~m}$ ("main subplot", Fig. 2); the other four pairs of subplots ("satellite subplots") have a size of $3 \times 3 \mathrm{~m}$. Roof and control subplots are in close proximity to each other (distance between roof and control ranges between 15 and $30 \mathrm{~m}$ for the main roofs, and between 6 and $15 \mathrm{~m}$ for the satellite subplots), in order to ensure similar subplot properties with respect to topography, soil and vegetation. A central overstory tree (Figs. 2, 3) is included in each of the central subplots, whereas the satellite subplots do not contain any large trees. The selected central trees are similar in age, size and canopy structure.

The roofs have a height of around $2 \mathrm{~m}$ and are supported by an unpainted timber construction leveled on a foundation of bricks or wooden support (Fig. 3a, b). All four sides of the timber construction are open in order to provide sufficient circulation and exchange with ambient air and to avoid heatup and changes in air humidity. Due to the roof dimensions, it was not possible to circumvent supporting constructions in the center of the roofed area, but they were kept at a minimum to reduce shading.

The roofs are covered with transparent POLYLUX ${ }^{\odot}$ trapezoidal corrugated panels (Fig. 3c). To allow a flexible reduction of precipitation, we decided to adjust the number of roof panels on a pre-defined time interval. In order to avoid any spatial persistent reduction of precipitation, we manually changed the position of the roof panels randomly in space. The roof panels of the large roofs have a size of $1.16 \mathrm{~m} \times 1.33 \mathrm{~m}=1.543 \mathrm{~m}^{2}$ and those on the small satellite roofs $0.9 \mathrm{~m} \times 0.58 \mathrm{~m}=0.522 \mathrm{~m}^{2}$. The main roof allows for $48 \times 7=336$ possible positions for the roof panels. Complete coverage - without overlapping of panels - is realized with 56 units (covering $100 \%$ ). The satellite roofs hold $22 \times 4=66$ possible positions and are at maximum covered with 12 small roofing units (covering: $100 \%$ ). The coverage of the roofs is adjusted every month by manually adding/removing and repositioning the roof panels. The timber construction and gutters themselves already intercept $11 \%$ (main roofs) and $15.5 \%$ (satellite roofs) of precipitation.

Rainwater from the roof panels and the timber construction is collected by rain gutters mounted along the roof frame 

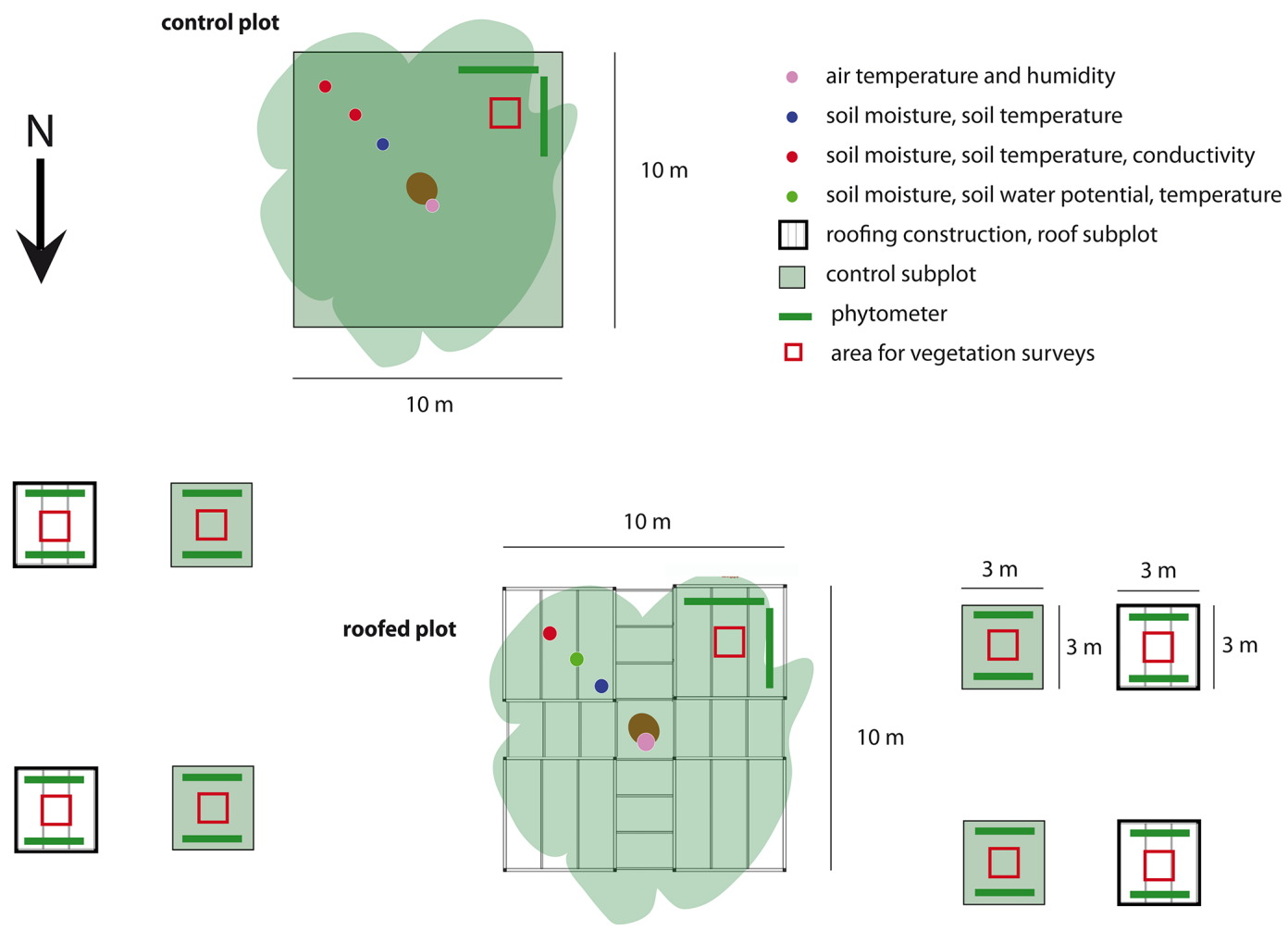

Figure 2. Schematic sketch of roofed and control subplots with roof construction indicated.

Table 2. General properties of the nine experimental plots.

\begin{tabular}{llllll}
\hline Exploratory & Plot name & $\begin{array}{l}\text { Mean annual } \\
\text { precipitation }\end{array}$ & $\begin{array}{l}\text { Mean annual } \\
\text { temperature }\end{array}$ & $\begin{array}{l}\text { Elevation } \\
\text { ma.s.l. }\end{array}$ & Soil class \\
\hline Schwäbische Alb & AEW8 & & & $766 \mathrm{~m}$ & Cambisol \\
& AEW13 & $940 \mathrm{~mm}$ & $6.5^{\circ} \mathrm{C}$ & $714 \mathrm{~m}$ & $\begin{array}{l}\text { Cambisol } \\
\text { AEW29 }\end{array}$ \\
& & & $760 \mathrm{~m}$ & Leptosol \\
\hline Hainich-Dün & HEW3 & & & $410 \mathrm{~m}$ & Luvisol \\
& HEW12 & $533 \mathrm{~mm}$ & $7.2^{\circ} \mathrm{C}$ & $332 \mathrm{~m}$ & Luvisol \\
& HEW47 & & & $333 \mathrm{~m}$ & Stagnosol \\
\hline Schorfheide-Chorin & SEW16 & & & $69 \mathrm{~m}$ & Cambisol \\
& SEW48 & $589 \mathrm{~mm}$ & $8.5^{\circ} \mathrm{C}$ & $74 \mathrm{~m}$ & Cambisol \\
& SEW49 & & & $65 \mathrm{~m}$ & Cambisol \\
\hline
\end{tabular}

and is drained into rain barrels. Stemflow (of all roofed beech trees) is also collected and drained to the rain barrels by a stem rim (Fig. 3d). The water level in the rain barrels is continuously logged with a pressure transducer to quantify the total amount of water removed by the roof. Above a certain water level, the barrel is emptied through an electromagnetic valve and the water is conveyed through a hose away from the roof. Eight of the nine plots are situated at very flat angledslopes, therefore re-entering of the water is prevented. Only plot AEW8 is situated on a steeper slope, which made compromises in the construction necessary; to balance the differences in height of the central roof, one side of the roof is placed directly on the ground without wooden support, the other is $3.2 \mathrm{~m}$ above ground. Nevertheless, the roof has the same dimensions, rain gutters and instrumentation as the other eight plots. No adjustment had to be made at the smaller satellite roofs at this plot.

To avoid shading and uncontrolled overflow of rainwater, all roofing units, as well as rain gutters, downpipes and barrels were cleaned periodically. This roof system can reduce rainfall between 11 and $100 \%$ and due to its design, rainfall exclusion is variable and not persistent in space. It holds the advantage of not only having the same temporal and spatial variability of water input distribution (where no covering 

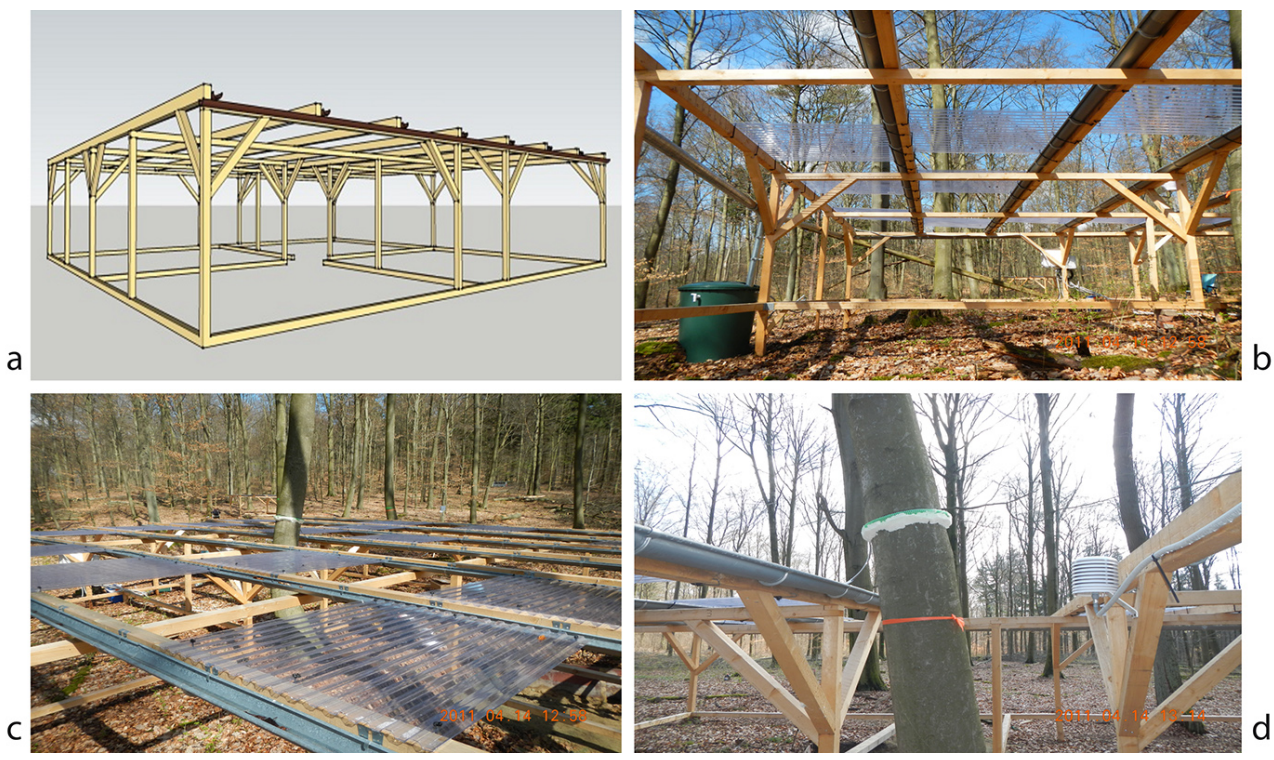

Figure 3. Roof construction sketch of the main roof $(10 \times 10 \mathrm{~m}) \mathbf{( a )}$. Roof with panels, rain gutters, water barrel and main tree (b, c). Roof detail with main tree and stem rim to collect stem flow (d). All pictures were taken at plot SEW48.

takes place) as the surrounding forest, but also of preserving the hydrochemical composition. This would not be the case if precipitation was completely intercepted and tap or river water was used for monthly irrigation.

\subsection{Rainfall reduction for realistic drought conditions}

Our target rainfall reduction level was a total annual precipitation input equivalent to a drought with a 40 year return interval. However, any other target value can be defined with the roof construction described above. We assume that the relative reduction in measured gross precipitation is equal to the relative reduction in throughfall under the forest canopy. The target value of the precipitation reduction was calculated from long-term precipitation data (1950-2010) using climate stations of the German Weather Service (DWD) in the vicinity of the investigation sites (Schorfheide-Chorin: DWD station Angermünde (ID 00164); Hainich-Dün: Erfurt-Bindersleben (ID 00487); Schwäbische Alb: Münsingen/Apfelstetten (ID 03402)). Annual precipitation varies in the observation period between 322 and $714 \mathrm{~mm}$ in Angermünde, between 295 and $767 \mathrm{~mm}$ in Erfurt-Bindersleben, and between 618 and $1228 \mathrm{~mm}$ in Münsingen/Apfelstätten.

The 2.5 percentile of the annual precipitation, corresponding to a drought with a 40 year interval, was derived for each climate station, the result of which was used as the target value for the reduction of the precipitation on the roofed plots. The target value for the reduced annual precipitation sum at the Schorfheide-Chorin site is $392 \mathrm{~mm}$, which corresponds to an average reduction of the incoming precipitation by $27 \%$. The target values for Hainich-Dün and Schwäbis- che Alb are 355 and $700 \mathrm{~mm}$ corresponding to a reduction of 33 and $26 \%$, respectively (Fig. 4).

The practical implementation of the precipitation reduction on the plots involves a monthly adjustment of the percentage of reduction (i.e., the number of roof panels) and their spatial distribution (i.e., the position of the panels on the roof). Therefore, the target values for the reduced annual precipitation sum were transferred to monthly target sums. To preserve the inter-annual variability, we calculated the monthly target sum by weighting the average monthly sum (i.e., one twelfth of the annual target sum) by the ratio between the long-term mean precipitation sum of each calendar month and the mean annual precipitation sum (Eq. 1).

$a_{m_{i}}=a_{\mathrm{a}} \times \frac{P_{\text {mean } m_{i}}}{P_{\text {mean } a}}$,

where $a_{\mathrm{m}}$ is the monthly target sum of a given month $i ; a_{\mathrm{a}}$ is the annual target sum (2.5\% percentile of annual precipitation); $P_{\text {mean } m_{i}}$ is the long term mean precipitation of given month $i ; P_{\text {mean } a}$ is the annual mean precipitation.

To calculate the reduction actually required, the reduced precipitation input under the roofs of the current month is compared with the target values. If the antecedent input fits the target value, the reduction is set to the theoretical reduction obtained from the long-term series for the month to achieve the target value. If the antecedent input under the roof is above or below the target value, the reduction is set higher or lower according to the magnitude of deviation.

Though reduction is calculated for the entire year, the roof remains uncovered from first snowfall until the end of the snow season, to avoid roof damage from a heavy snowpack. During this period, precipitation was only reduced by $11 \%$ 

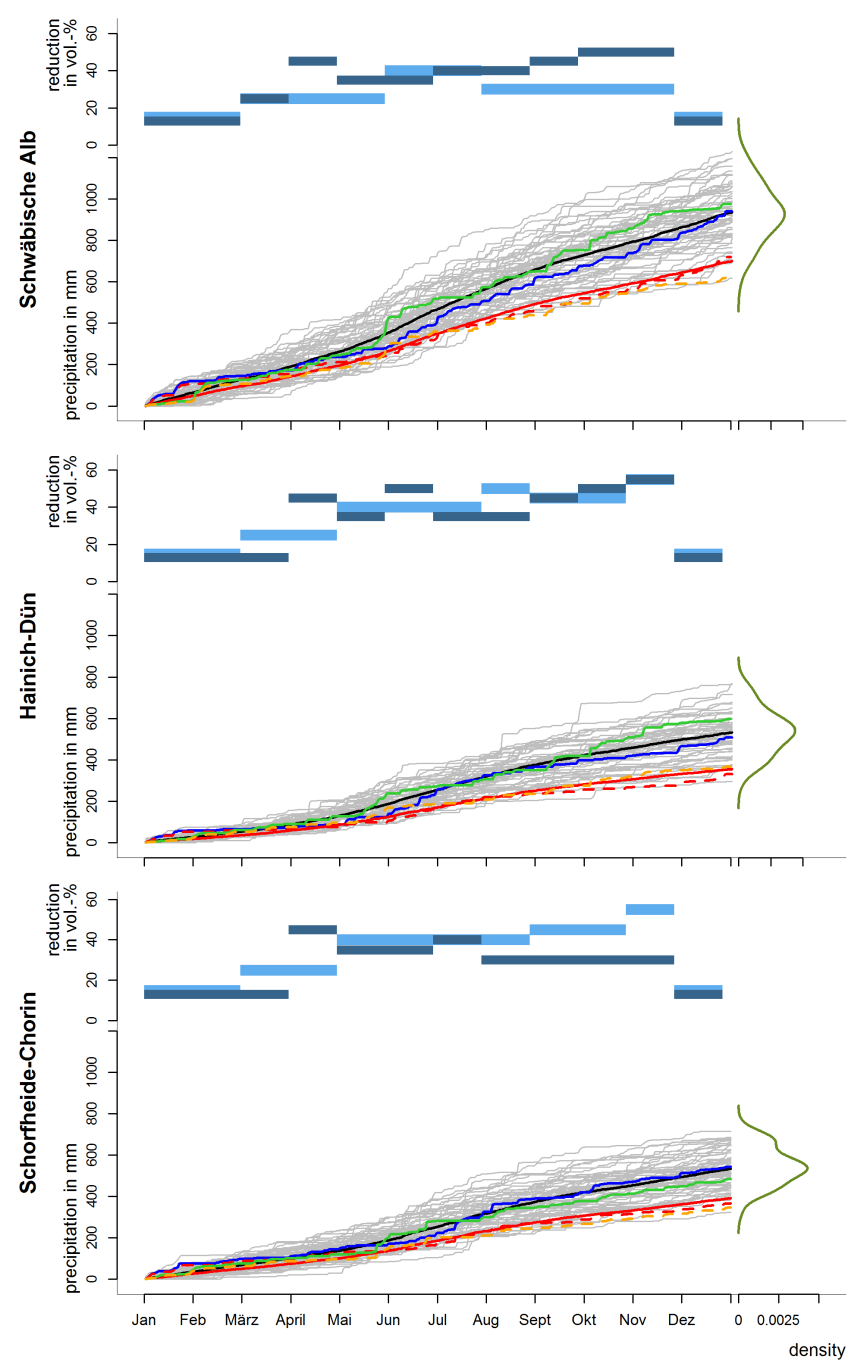

density

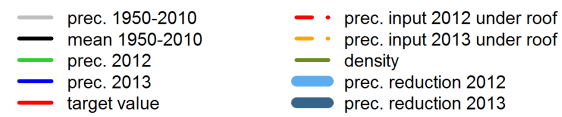

Figure 4. Cumulated sums of precipitation. Grey lines: individual years 1950-2010. Black line: cumulated mean of 1950-2010. Dark green line: appearance distribution of precipitation 1950-2010 (density). Light blue bars: reduction of precipitation 2012 in vol \%. Dark blue bars: reduction of precipitation 2013 in vol \%. Blue line: cumulated precipitation of year 2012. Green line: cumulated precipitation of year 2013. Solid red line: cumulated $2.5 \%$ percentile (target value). Dashed red line: cumulated precipitation under roofs in 2012. Dashed orange line: cumulated precipitation under roofs in 2013.

(for the main roof and $15.5 \%$ for the satellite subplot roof, for construction reasons) from mid-November/early December until January/February. To account for the absent reduction in winter months, the reduction in spring balances winter-month excess or deficit. Similarly, November reduction can be increased to create a reserve for wet winter months.

\subsection{Monitoring and sampling}

The effects of the imposed precipitation reduction on the atmosphere and soil were continuously monitored under the central roof subplots and compared with parallel measurements and sampling campaigns at the central control subplots. The central subplots are divided into four sectors: one for field experiments and soil sampling, one for vegetation surveys and experiments, one for long-term soil-hydrological monitoring, and one remains untouched and is reserved for possible future investigations (Fig. 2). The satellite control and roof subplots are used exclusively for vegetation surveys and soil sampling for microbial analyses.

\subsubsection{Meteorology and soil hydrology}

Monitoring at the main subplots includes measurements of soil moisture and soil temperature (5TM, Decagon Devices Inc.), soil electrical conductivity (5TE, Decagon Devices Inc.) and only under the roofs matric potential (MPS-2, Decagon Devices Inc.) at 2, 3, and $4 \mathrm{~m}$ distance from the central tree, and in four soil depths $(5,15,30$, and $60 \mathrm{~cm})$. At the shallow sites (HEW3, HEW12, HEW47, AEW8, AEW13, AEW29), the $60 \mathrm{~cm}$ depth probes were omitted in at least one distance from the central tree. The measuring accuracy according to the technical data sheets of the 5TE and 5TM probes is $\pm 1{ }^{\circ} \mathrm{C}$ for temperature, $\pm 10 \%$ of the measured value for electrical conductivity (5TE only), and $\pm 15 \%$ of the measured value for the volumetric water content. The MPS-2 probes have an accuracy of $\pm 25 \%$ of the reading (as per technical data sheet) within the measuring range of -5 to $-100 \mathrm{kPa}$. To observe possible roof effects on the microclimate, air temperature and humidity sensors (HMP45C with HUMICAP ${ }^{\circledR} 180$ sensor, Campbell Scientific Inc.) were installed at one location under the central roof and one at the central control subplot at the same height $(2 \mathrm{~m})$ above the ground. The HMP45C temperature and humidity probes have an error in temperature measurement of \pm 0.2 to $\pm 0.3{ }^{\circ} \mathrm{C}$ and $2-3 \%$ for air humidity. Sap flow in the central trees is monitored using the three-needle heat-pulse sensor by EAST 30 Inc. with an accuracy of around $5 \%$ of the reading (Cohen et al., 1981). All data (soil, climate, and sap flow) are logged at $15 \mathrm{~min}$ intervals, except the water level in the rain barrels, which are logged at $1 \mathrm{~min}$ intervals. In addition, measurements of photosynthetic active radiation were carried out periodically.

\subsubsection{Botanical parameters and evapotranspiration}

To address the influence of the imposed drought on the forest understory, we established, at each plot, ten vegetation recording sub-subplots, each with an area of $1 \times 1 \mathrm{~m}$. These sub-subplots were marked and were not entered during the rain exclusion experiment. For each sub-subplot, we determined plant species to identify the understory vegetation 
community and its cover. The baseline survey for all plots took place between June 2011 and July 2011.

At each subplot the specific leaf area index (LAI) was determined from randomly selected field-fresh leaves from all species with a coverage of more than $5 \%$ (fresh weight per leaf sample $>1 \mathrm{~g}$, which equals $2-12$ leaves per species). Measurements were made three times in 2012 (spring - April, early summer - June/July, late summer - August/September) at all nine plots. Digital photos, which were taken of these leaves in the field, were used to determine the average area of a leaf $\left(\mathrm{LA}_{\text {species}}\right.$; defined as the area of an average leaf of a given species) using the image analysis software imageJ 1.45s (Abramoff et al., 2004). For understory analysis, we took digital photos of four randomly chosen quadratic areas per control and roof sub-subplots $\left(n=4 ; A_{\text {total }}=2.45 \mathrm{~m}^{2}\right)$ and counted the total number of leaves ( $\left.N_{\text {leaves }}\right)$ of each species within the known groundsurface area $\left(A_{\text {total }}\right)$. LAI was calculated by the following equation:

$\mathrm{LAI}=\frac{\sum_{i}^{N_{\text {species }}} N_{\text {leaves }} \times \mathrm{LA}_{\text {species }}}{A_{\text {total }}}$,

where $N_{\text {species }}$ is the total number of species found on the quadratic area of $2.45 \mathrm{~m}^{2}$. For subplot plant species richness we counted the total species number on the digital photos of the $2.45 \mathrm{~m}^{2}$ areas for each treatment.

For further insight into the effect of drought on growth, we planted phytometers (proxy plants used as a measure of plant physical response) of Fagus sylvatica L. on all 90 subplots. We used 1-year-old F. sylvatica saplings (Schlegel \& Co. Gartenprodukte GmbH, Riedlingen, Germany) in October 2011 from three different provenances corresponding to the three different experimental sites. The saplings had an initial height of $30-50 \mathrm{~cm}$ (with a mean and sd of $34.74 \mathrm{~cm} \pm 8.15 \mathrm{~cm}$, respectively) and a tap root length approximately of $10 \mathrm{~cm}$. At the time of planting, roots of all saplings were pruned to $10 \mathrm{~cm}$ to avoid crooked roots in shallow soils, as they occur at the Hainich and Schwäbische Alb site. In October and November 2011, we either planted the beech saplings into the resident plants or once removed the total aboveground biomass of all herbaceous plants in a radius of $20 \mathrm{~cm}$ around the phytometer to exclude herb layer competition. In total we planted 1080 beech phytometers $(90$ subplots $\times 12$ individuals). For further information on the experimental design of the phytometer experiment see Baudis et al. (2014).

Growth of all planted beeches was recorded by measuring different growth response variables such as leaf number, plant height, leaf length and crown expansion and compared with the phytometer data of the control plots. The phytometers were monitored three times in 2012 (spring, early summer, late summer). Relative growth rates (RGR) were calculated from April 2012 to July 2012. Leaf stomatal conduc- tance $\left(g_{\mathrm{s}}\right)$ was measured on all monitoring dates with a SC-1 leaf porometer (Decagon Devices Inc.).

In the field, gas-exchange chambers (transparent Perspex, size: $52 \times 77.5 \times 78.5 \mathrm{~cm}, A=0.61 \mathrm{~m}^{2}$ ) comparable to the ones described in Yepez et al. (2005) were used for measuring understory evapotranspiration (ET) rates. The chambers were open to the soil, sealed with rubber foam gaskets to the ground and were used as closed systems to assess the build up of water vapor from soil evaporation and plant transpiration. Measurements were made three times in 2012 (spring, early summer, late summer) at all nine plots. ET rates were determined on the control subplots and on the roof subplots. The increase in water vapor in the closed chambers was measured with a cavity ring-down laser spectrometer (PICARRO L1102-I, Picarro Inc.) directly in the field, with four replicates per control subplot and per roof subplot between 10:00 a.m. and 15:00 p.m. (CEST). The chamber air was circulated through the isotope water analyzer via a low absorption tube using the Picarro pump (flow rate $<0.4 \mathrm{~L} \mathrm{~min}^{-1}$ ) and fed back again in the chamber headspace. For each chamber, a measurement lasted $10-12 \mathrm{~min}$, and a fan provided mixing of the air in the gas exchange headspace. Temperature, air humidity (VP-3 humidity temperature and vapor pressure sensor; Decagon Devices Inc.) and photosynthetic photon fluency rate (PPFR) were continuously logged (Par Photon Flux Sensor, Decagon Devices Inc.). ET rates were calculated from the linear increase in water vapor concentration determined by the laser spectrometer in the chamber over time and based on the ground area.

\subsection{Statistical analyses}

We applied $t$ tests to assess the differences in the LAI and for species richness between the roof and control treatment using R (R-3.0.2, The R Foundation for Statistical Computing 2013).

Response variables for growth and stomatal conductance of the understory beech phytometers were evaluated with linear mixed effects models with site (three different experimental sites), drought (sheltered or not), competition (with and without competition) and provenance (SchorfheideChorin, Hainich-Dün, and Schwäbische Alb) as fixed factors and plot, subplot nested in plot and sub-subplot nested in plot as random factors. The statistical analyses were carried out with the R-Studio software (version 0.97.248; R version 3.0.0) using the "nmle" package. Air temperature and humidity were tested with the Wilcoxon-Mann-Whitney rank sum test R-Studio software (version 0.97.248; R version 2.15.2) using the "stats" package. 


\section{Results}

\subsection{Precipitation reduction}

All roofs were installed during fall/winter 2011 (midSeptember in Schorfheide-Chorin, mid-October in HainichDün, early December in Schwäbische Alb). On all plots the rain exclusion started on 1 March 2012 and ended on 30 November 2013. Continuous monitoring of meteorological and soil hydrological data started in Schwäbische Alb in mid-April 2012 and in Schorfheide-Chorin and Hainich-Dün at the end of August 2012.

With respect to precipitation, the year 2012 was an average year with a total precipitation of $940 \mathrm{~mm}(100.4 \%$ of long term mean) in the Schwäbische Alb, $508 \mathrm{~mm}(95.5 \%)$ in Hainich-Dün, and $543 \mathrm{~mm}$ (101.5\%) in Schorfheide-Chorin (Fig. 4, blue lines). At all sites in 2012, winter rain and snowfall was greater than average. In contrast, the year 2013 was wetter than the long term mean in Schwäbische Alb (976 mm, 104.3\%) and Hainich-Dün (596.5 mm, 112.1\%), and drier in Schorfheide-Chorin $(483.2 \mathrm{~mm}, 90.4 \%)$. To compensate for the high precipitation input, we had to raise the exclusion (Fig. 4, blue bars) from 30\% (mean value) to $50 \%$, which resulted in a reduction below the target $(699 \mathrm{~mm})$ of $11 \%$. Generally, the reduced precipitation input on all plots satisfyingly reached the target values, both in 2012 and in 2013. The reduced input (dashed red and orange lines in Fig. 4) hovered around the target value (solid red line), depending on the monthly adaption of the roof cover. The maximum applied roof coverage in 2012 and 2013 was $55 \%$.

In total, $221 \mathrm{~mm}$ were excluded in the Schwäbische Alb sites in 2012 which resulted in an incoming precipitation under the roofs of $719 \mathrm{~mm}$. In Hainich-Dün and SchorfheideChorin, 178 and $176 \mathrm{~mm}$ respectively were reduced (input under the roof: 331 and $366 \mathrm{~mm}$ ). In 2013, incoming precipitation under the roof was 619,366 and $346 \mathrm{~mm}$ for Schwäbische Alb, Hainich-Dün, and Schorfheide-Chorin respectively, which hit the target values satisfyingly; in addition, Schwäbische Alb and Schorfheide-Chorin had a reduction below the target (11\% for both sites) (Fig. 4).

\subsection{Roof effect on air temperature, air humidity and soil temperature}

In general, roofing on experimental plots can promote changes of air temperature and humidity, due to alterations of radiation and ventilation (greenhouse effect). In fact, some authors actually used roofing setups in order to achieve higher mean temperatures, mainly as an effect of preventing the nocturnal emission of longwave radiation (e.g., Selsted et al., 2012). Because elevation of air temperature and humidity has significant effects on growth, germination, transpiration and water uptake of plants, on microbial activity and on soil evaporation, we aimed at avoiding any alteration of air temperature and humidity as well as radiation. Based on the monitored air temperature, air humidity and soil temperature at the main roof and the neighboring main control subplot, we tested whether the roofing had a measurable effect on these variables. Air temperature and humidity were not affected by the roofing on any of the experimental sites (Fig. 5). The 15 min readings on the control plot and under the roof are not significantly different (except plot HEW3) according to the Wilcoxon-Mann-Whitney rank sum test.

Similar to air temperature, mean values of soil temperature show no difference between main control and main roofed subplot regarding to the measuring accuracy of the 5TM/5TE-probes in all depths (data not shown).

\subsection{Roof effect on soil moisture}

As expected, the roof coverage had an immediate effect on the soil water content. However, the response to the reduced precipitation input varied between the sites. Figure 6 shows the soil water deficit on the main roofed subplots when compared with the neighboring main control subplots for the different measuring depths and distances from the central trees at the subplots for the example month May 2013 (similar results were obtained for the other months). SchorfheideChorin (Fig. 6, bottom) showed the lowest reduction of all sites with little difference between the soil moisture of the roofed and control subplots. The top soil layer of beech plots SEW48 (4 m distance) and SEW49 ( 2 and $3 \mathrm{~m}$ distance) even exhibited a small increase in soil moisture. The difference between roofed subplot and control subplot are more pronounced in Schwäbische Alb and Hainich-Dün than in the Schorfheide-Chorin plots for this time period. In HainichDün (Fig. 6, middle), the highest soil moisture reduction appeared in the spruce plot HEW3, especially in the top layer ( $5 \mathrm{~cm}$ depth), where all distances to the central tree showed high deficits compared to the control subplot. In contrast, HEW12 and HEW47 (both beech) did not show such high reduction rates in the top layer. In HEW47, no difference $(15 \mathrm{~cm}$ depth in 3 and $4 \mathrm{~m}$ distance and $30 \mathrm{~cm}$ depth in $4 \mathrm{~m}$ distance), and in both plots (HEW12: $30 \mathrm{~cm}$ depth, $4 \mathrm{~m}$ distance; HEW47: $60 \mathrm{~cm}$ depth, $2 \mathrm{~m}$ distance) even a small increase of soil moisture on roofed subplots compared to control subplots appeared. In general, the Schwäbische Alb plots (Fig. 6, top) exhibited the highest soil moisture reduction of all the sites. The reduction was strongest in the top soil layer $(5 \mathrm{~cm})$ of all plots at a distance of 3 and $4 \mathrm{~m}$ from the center tree. In addition, the $2 \mathrm{~m}$ distance $(5 \mathrm{~cm}$ depth) of AEW8 and AEW13 and the $3 \mathrm{~m}$ distance $(15 \mathrm{~cm}$ depth) of AEW8 showed high soil moisture deficits. On AEW8 and AEW29 (both beech), $15 \mathrm{~cm}$ (AEW8 and AEW29) and $30 \mathrm{~cm}$ (AEW8) sensors did not detect soil moisture differences between the roofed and control subplots. 


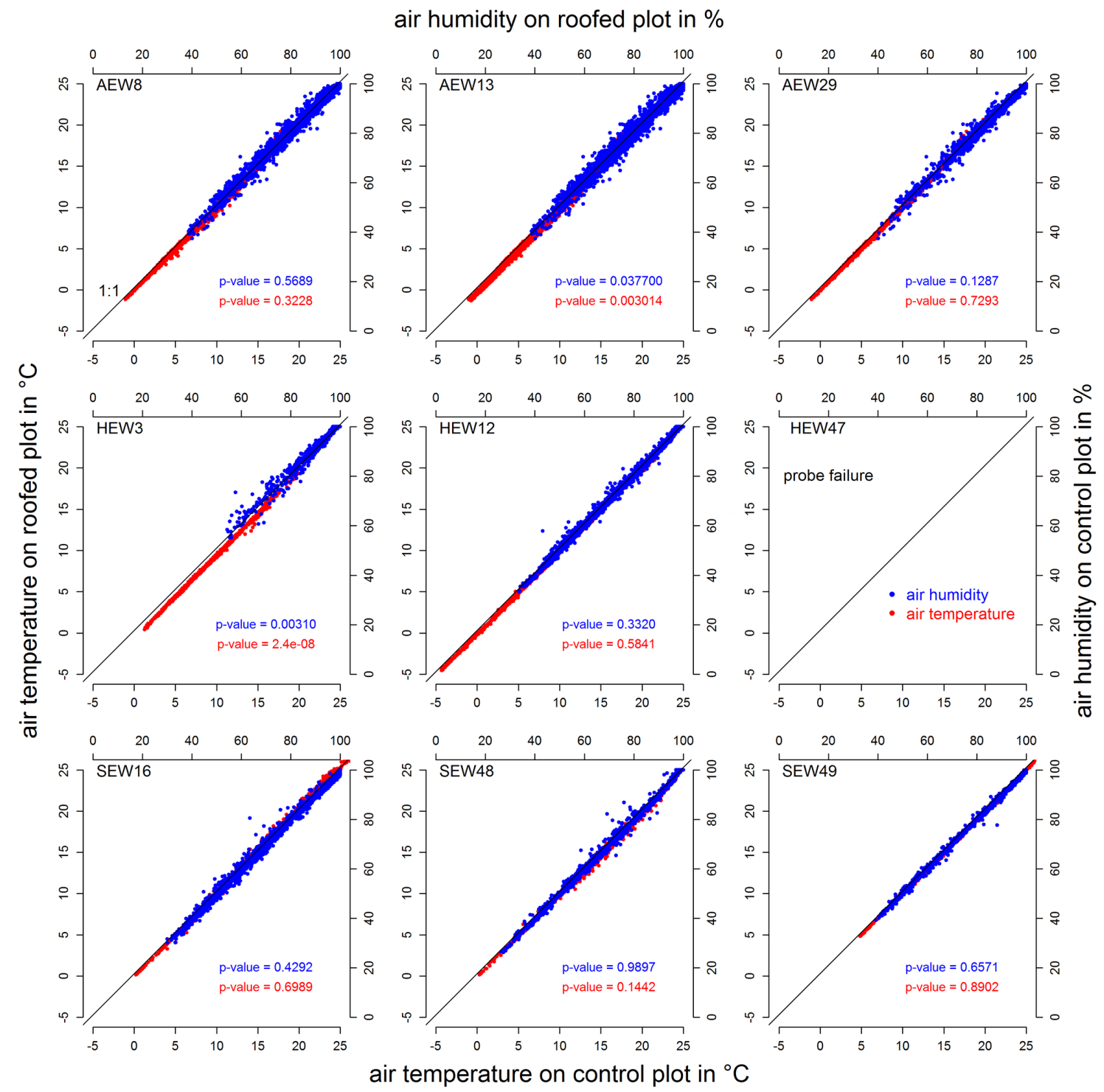

Figure 5. Air temperature control plots vs. air temperature roofed plots (red dots) and air humidity on control plots vs. air humidity on roofed plots (blue dots) for all experimental sites in May 2013. No data for HEW47 are shown due to probe failure.

\subsection{Plant community and phytometer}

There were no significant differences between the total vegetation coverage of the sites $(27.9,40.3$, and $38.9 \%$ - average of the three plots per site of Schorfheide-Chorin, HainichDün, and Schwäbische Alb, respectively). The type of the understory plant community as assessed in the vegetation surveys is given in Table 1. A detailed overview of the different functional groups (grass, herb, shrub, and tree recruits) and the mean coverage on the nine plots can be found in Table 3. Most plots are dominated by grasses and herbs; subplots differ in total coverage between 2.26 and $57.1 \%$. (Table 2).

In late summer 2012, i.e., at the end of the first growing season with the drought treatment, there were significant differences in $L A I$ between the roof and control subplots at the managed beech plot at the Schwäbische Alb (AEW29; $p=0.001$ ) and at the intensively managed conifer plot at the Hainich exploratory (HEW03; $p=0.01$ ) (Table 4). The species richness of the understory plant community was significantly higher at the managed roof subplot of the Hainich exploratory compared to the control subplot (HEW47, $p=$ 0.004). Table 5 summarizes the drought effects on leaf stomatal conductance $\left(g_{\mathrm{s}}\right)$ of the planted phytometer as a shortterm response to drought. Leaf stomatal conductance was reduced under the roofs, with a more significant reduction in July $2012(p=0.0009)$ than in September 2012 (marginally significant $p=0.0602)$ (Table 5). 
Table 3. Results of the vegetation monitoring of the understory vegetation for various functional groups at all three sites shown as mean coverage per plot in percent; calculated as a mean from ten vegetation recordings of $1 \times 1 \mathrm{~m}$ per subplot.

\begin{tabular}{llrrrrr}
\hline Exploratory & Plot name & $\begin{array}{c}\text { Understory } \\
\text { vegetation } \\
\text { cover }(\%)\end{array}$ & & \multicolumn{2}{c}{ Mean cover in functional group (\%) } \\
\cline { 3 - 6 } & & & Grass & Herb & Shrub & Tree recruits \\
\hline Schwäbische Alb & AEW8 & 22.87 & 0.73 & 19.90 & 0.00 & 2.30 \\
& AEW13 & 57.10 & 0.65 & 50.10 & 3.90 & 3.20 \\
& AEW29 & 36.77 & 5.60 & 20.80 & 0.00 & 10.50 \\
\hline Hainich-Dün & HEW3 & 48.95 & 19.70 & 26.60 & 1.15 & 0.20 \\
& HEW12 & 44.67 & 0.00 & 34.0 & 0.00 & 10.70 \\
& HEW47 & 27.30 & 8.00 & 9.20 & 0.00 & 10.40 \\
\hline Schorfheide-Chorin & SEW16 & 33.60 & 28.60 & 5.00 & 0.00 & 0.00 \\
& SEW48 & 2.26 & 1.80 & 0.43 & 0.00 & 0.10 \\
& SEW49 & 47.90 & 0.03 & 39.40 & 7.50 & 1.30 \\
\hline
\end{tabular}

Table 4. LAI (mean $\pm \mathrm{SD}, n=4)$ and species richness $\left(A_{\text {total }}=2.45 \mathrm{~m}^{2}\right)$ for control and roof subplots in late summer (August/September) 2012 for the different exploratories and management types. "No veg." means no vegetation on plot; $t$ tests were applied to assess the differences in the LAI and species richness between the roof and control treatment; ${ }^{*} p<0.05,{ }^{* *} p<0.01$.

\begin{tabular}{|c|c|c|c|c|c|c|c|}
\hline \multirow[b]{2}{*}{ Plot } & \multirow[b]{2}{*}{$\begin{array}{l}\text { Management } \\
\text { type }\end{array}$} & \multicolumn{3}{|c|}{ LAI } & \multicolumn{3}{|c|}{ Species richness } \\
\hline & & Control & Roof & $\begin{array}{l}\text { Roof vs. } \\
\text { control }\end{array}$ & Control & Roof & $\begin{array}{l}\text { Roof vs. } \\
\text { control }\end{array}$ \\
\hline AEW13 & Spruce & $1.74 \pm 0.41$ & $1.63 \pm 0.50$ & - & 9 & 8 & - \\
\hline AEW8 & Beech unmanaged & $0.75 \pm 0.21$ & $0.44 \pm 0.24$ & - & 5 & 4 & - \\
\hline AEW29 & Beech managed & $0.97 \pm 0.05$ & $0.71 \pm 0.06$ & $* *$ & 9 & 8 & - \\
\hline HEW3 & Spruce & $0.92 \pm 0.15$ & $0.53 \pm 0.09$ & $* *$ & 5 & 5 & - \\
\hline HEW12 & Beech unmanaged & $0.40 \pm 0.08$ & $0.24 \pm 0.09$ & - & 3 & 3 & - \\
\hline HEW47 & Beech managed & $0.37 \pm 0.04$ & $0.42 \pm 0.04$ & - & 6 & 8 & $* *$ \\
\hline SEW16 & Pine & $0.62 \pm 0.10$ & $0.44 \pm 0.13$ & - & 5 & 3 & - \\
\hline SEW48 & Beech unmanaged & No veg. & No veg. & - & No veg. & No veg. & - \\
\hline SEW49 & Beech managed & $0.63 \pm 0.18$ & $0.88 \pm 0.20$ & - & 8 & 7 & - \\
\hline
\end{tabular}

Additionally, there was an interaction of drought and site (Table 4; Fig. 7). While drought had no effect at the wettest site (Schwäbische Alb), stomatal conductance was reduced under the roof at the Schorfheide-Chorin and the HainichDün sites. In contrast to $g_{\mathrm{s}}$, growth parameter did not show significant drought effects in this early stage of the experiment.

At the beginning of the 2012 growing season, when the drought treatment had started, the understory evapotranspiration rates between the roof and control subplots as determined with chambers were not significantly different, indicating the initial comparability of the subplots (Fig. 8). In the late summer 2012 we detected no significantly lower ET rates with the chamber measurements as response to reduced precipitation with one exception at SEW16 (pine) (Fig. 8).

\section{Discussion}

\subsection{Precipitation reduction}

The aimed reduction of precipitation to a 40-year annual drought equivalent $(2.5 \%$ percentile) was met. The annual precipitation of the years 2012 and 2013 were in all regions close to the long term annual mean. Possible problems may occur when using our technique in extraordinarily dry or wet years, although we did not detect such meteorological circumstances in the 1950-2010 records in all our regions when we tested our design in terms of figures.

In contrast to other constructions used in rainfall reduction experiments (see the reviews of Beier et al., 2012; Wu et al., 2011), it was possible to reduce the precipitation to a certain level over the year, instead of excluding the total precipitation input during a time period (e.g., Kopittke et al., 2014; Glaser et al., 2013). Though untested, our construction 

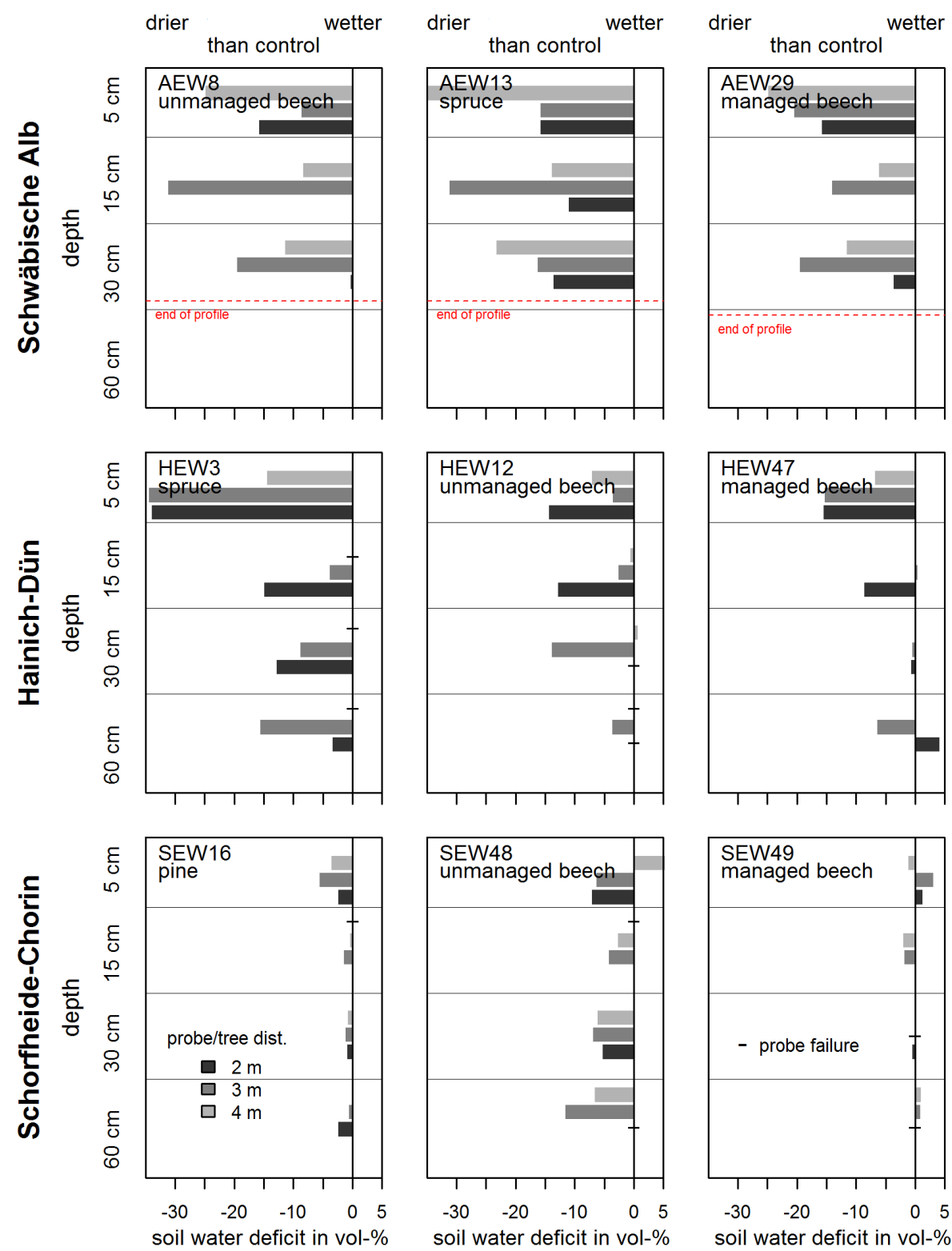

Figure 6. Soil water deficit (soil water content of control minus roofed subplot) of the main subplots. All values originate from May 2013, except the values from HEW47 (April 2013), due to probe failure. “-” marks missing values.

is flexible enough to realize a wide range of reduction experiment designs, e.g., total reduction during distinct growing season periods (manipulation of inter-annual variability), shorter adjustment intervals of roofing panels (daily, weekly) and combination with irrigation equipment (e.g., Glaser et al., 2013; Fay et al., 2000). The roofing design can be enlarged or reduced in size to meet the requirements of a site or experimental design. Experimental drought or rainfall exclusion experiments are often extended over 1-2 years (Parra et al., 2012; Dermody et al., 2007), but our construction can be used to study long-term drought effects for several years due to the stability of the timber construction.

\subsection{Roof effect on air temperature, air humidity and soil moisture}

As mentioned above, roofing on experimental plots can have a significant effect on air temperature and humidity. Temperature controls - as a main effect - the duration of the growth period, but also influences processes like photosynthesis, respiration, and transpiration (Maracchi et al., 2005). The shielding can raise mean air temperature by 1.2 to $1.4^{\circ} \mathrm{C}$ as reported by Glaser et al. (2013) and can reach as much as $3 .{ }^{\circ} \mathrm{C}$ (Selsted et al., 2012). In contrast to other studies (Selsted et al., 2012; Parra et al., 2012; Dermody et al., 2007), we aimed to avoid these "greenhouse" effects, to separate 
Table 5. Results of the linear mixed model for the leaf stomatal conductance $\left(g_{\mathrm{s}}\right)$ as a function of site, drought and competition of the Fagus sylvatica phytometers in July and September 2012 (spring data not shown). Values are $p$ values. Significant probabilities $(p<0.05)$ are shown on bold; den $\mathrm{df}=$ degrees of freedom.

\begin{tabular}{lrrrr}
\hline \multirow{2}{*}{ Factor } & \multicolumn{4}{c}{ Leaf stomatal conductance } \\
\cline { 2 - 5 } & den df & $g_{\mathrm{s}}$ (July) & den df & $g_{\mathrm{s}}$ (September) \\
\hline (Intercept) & 752 & $<0.0001$ & 690 & $<0.0001$ \\
Site & 6 & $\mathbf{0 . 0 2 5 4}$ & 6 & 0.3133 \\
Drought & 78 & $\mathbf{0 . 0 0 0 9}$ & 70 & 0.0602 \\
Competition & 84 & 0.7268 & 76 & 0.9837 \\
Site : drought & 78 & $\mathbf{0 . 0 4 7 3}$ & 70 & 0.1547 \\
Site : competition & 84 & 0.4376 & 76 & 0.8865 \\
Drought: competition & 84 & 0.1939 & 76 & 0.6987 \\
Site : drought : competition & 84 & 0.6997 & 76 & $\mathbf{0 . 0 2 1 9}$ \\
\hline
\end{tabular}

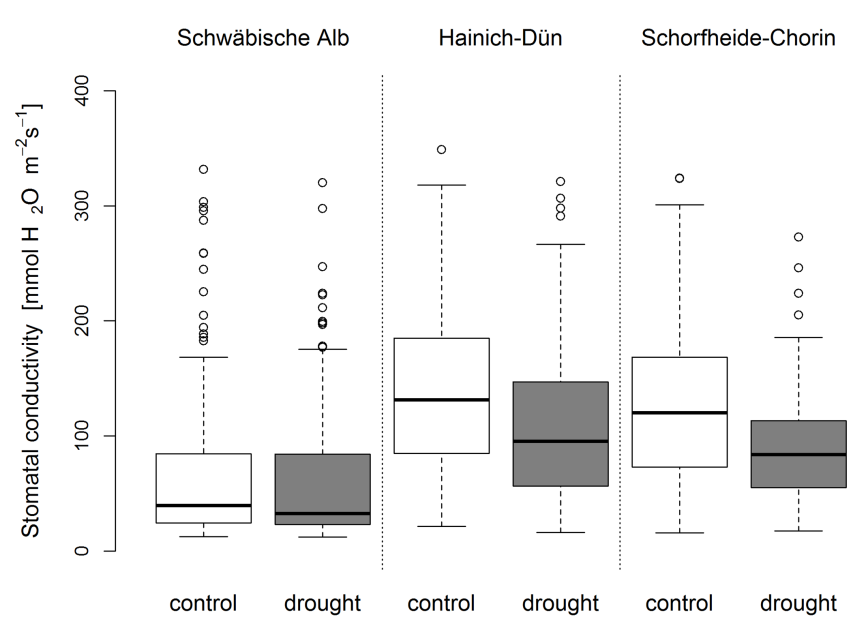

Figure 7. Leaf stomatal conductance at the three experimental sites in July 2012. The boxes show medians and quartiles, the whiskers show 1.5 times the interquartile range of the data. For statistical analyses, see Table 5 .

the effect of prolonged drought from effects due to changes in air temperature and air humidity conditions. Our measurements show no difference in humidity and air temperature between roofed and control plots, which clearly indicates a comparable coupling of the airspace close to the ground to the atmosphere on both subplots. In addition, the design of the roofs with an incomplete coverage $(2 \mathrm{~m}$ high, four sides open, maximum roof coverage $55 \%$, complete roof area only $100 \mathrm{~m}^{2}$ ) definitely did not represent a closed roof. Given that and the findings that air humidity and temperature remain totally unaffected, it is very unlikely, that $\mathrm{CO}_{2}$ concentrations increased under the roofs and thus also no $\mathrm{CO}_{2}$ fertilization effects are to be expected.

The drought treatment clearly reduced soil moisture content in all depths in all plots (exceptions are the $5 \mathrm{~cm}$ depths of SEW48 and SEW49, the $60 \mathrm{~cm}$ depths of HEW47 and SEW49). In Hainich-Dün and especially in the Schorfheide-
Chorin plots, soil moisture deficit decreased with depth. This is in line with the findings of English et al. (2005), who found a decrease of soil moisture deficit with depth. The reason for the difference in behavior of the Schwäbische Alb plots in soil moisture drought response is twofold: the reduction is always relative, not absolute, which leads to more pronounced deficits in areas with higher precipitation. Secondly, the Schorfheide plots, which showed the lowest deficits, are all sandy soils. This type of soil already has a comparably low soil moisture when untreated.

We acknowledge that the water relations in the soil under the roof might have been influenced by adult trees rooting partially outside and partially inside the sheltered area, mainly due to redistribution of water via the roots. As a consequence, the intensity of the reduction of soil water content might not only be affected by rainfall reduction and soil properties but also by the intensity of such redistribution.

\subsection{Roof effects on evapotranspiration, leaf stomatal conductance and growth}

Only a small number of plots have shown a significant change in LAI and species richness as a consequence of the treatment. This is in agreement with the findings from the phytometer experiments, where leaf stomatal conductance was reduced as an effect of the precipitation manipulation, while growth variables were not affected at that stage of the experiment. Our results show that reduced growth of understory plants and changes in community structure do not occur as an early response to drought in the first year under the applied precipitation reduction regime. Drought stress was not intense enough to induce mortality or strong changes in biomass of a particular species in the short term. This seems to be partially in contrast to the conclusion drawn by Leuzinger et al. (2011), that the initial responses of ecosystems to drought (or other parameters related to global change) are the highest and decline over longer time periods. The ecosystem's response time to changes in environmental conditions will, however, also depend on the treatment in- 

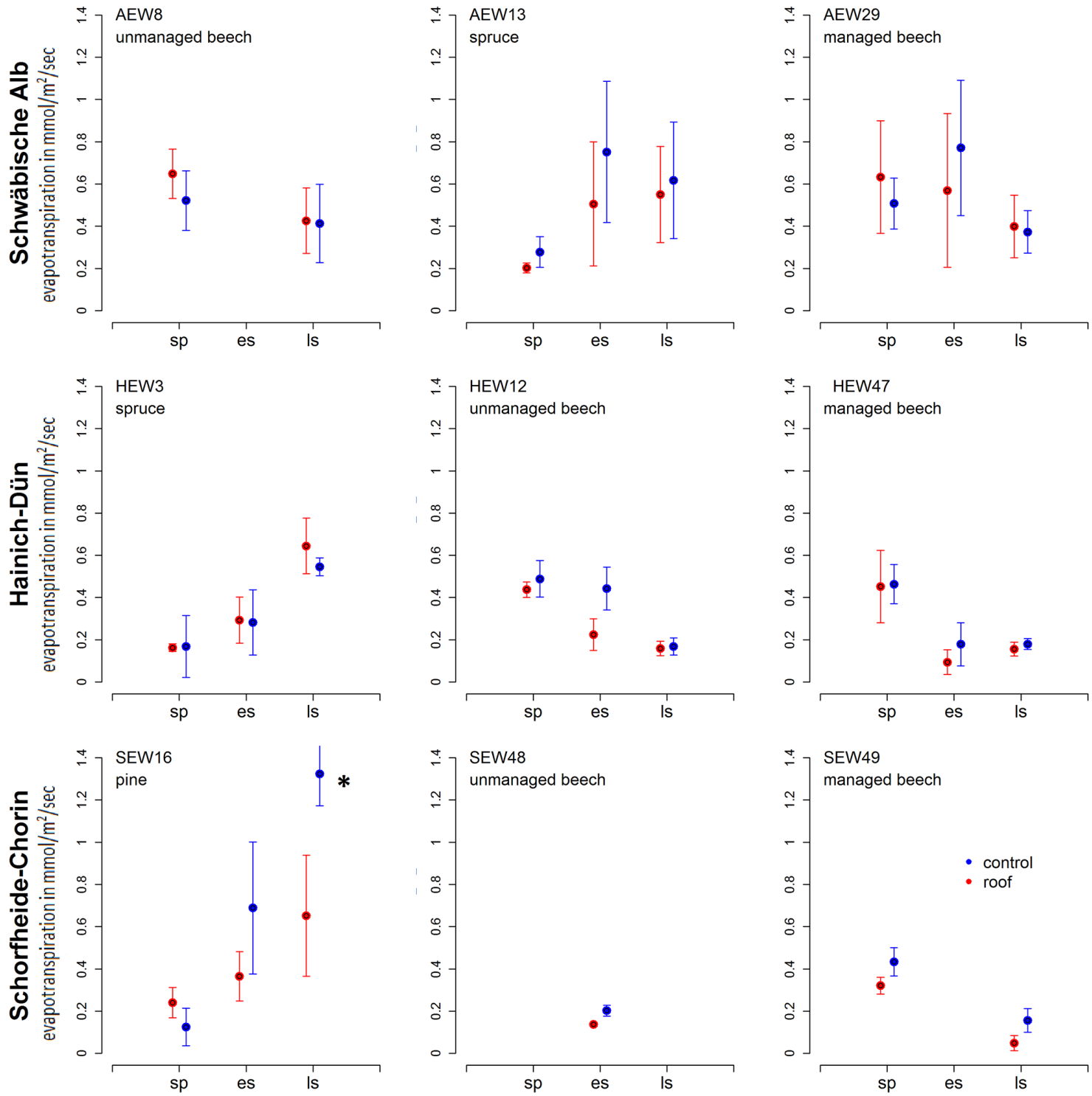

Figure 8. Mean evapotranspiration rates $( \pm \mathrm{SD})$ for control and drought treatments $(n=4)$ at different times during the growing season (sp: spring; es: early summer; 1s: late summer). Data are shown for the different management intensities (managed/unmanaged beech and pine/spruce) in the three exploratories. The asterisk marks significant differences ( $p$ value $<0.05$ ).

tensity. Changes in ecosystem functioning occur after stress conditions exceed a certain level of climate severity threshold, which can not be predicted yet (Bahn et al., 2014; Vicca et al., 2012). The achieved 40-year return interval drought was in our experiment not enough to push the system beyond this physiological and biochemical threshold.

Conversely, the quick response of leaf stomatal conductance $\left(g_{\mathrm{s}}\right)$ confirms that control of the transpiration is a very sensitive and short-term response of plants to reduced water supply (cf. Gessler et al., 2004). The finding that $g_{\mathrm{s}}$ was mainly reduced in July and only marginally significantly in September clearly reflects the fact that our rain reduction was not absolute but proportional. As the amount of rain- fall in September was much higher than in July, a proportional reduction had a smaller effect on the plants than in July. For the same reasons, we did not encounter a significant response to the drought treatment at the Schwäbische Alb, which was the wettest site. Recently Hommel et al. (2014) provided evidence that various forest understory species can respond to mild drought by reducing assimilation rates simultaneously with $g_{\mathrm{s}}$ or even before it. As a consequence, we need to expect effects of our treatment on carbon assimilation and biomass production, thus supporting our assumption that over the longer-term changes in coverage and vegetation structure are likely to occur. When scaling our results from leaf $g_{\mathrm{s}}$ to the understory ecosystem (evapotranspiration), the 
ET response to the drought treatment was only observed in the pine plot in the Schorfheide site during this initial phase. This points to the fact that the stomatal response observed at the leaf level in the phytometer plants does not yet scale with the ecosystem water use.

\section{Conclusions}

We conclude that our innovative roofing construction is a valid, and more realistic, alternative to the common drought simulation practice of total rainfall reduction. Due to the flexible construction, it is possible to preserve the temporal and spatial variability of rainfall pattern, in particular under the forest canopy, while reducing precipitation input and soil moisture and without changing the air temperature and humidity on site. During the first two years of treatment, the reduction of precipitation to a 40-year annual drought event did not introduce artificial vegetation responses as an effect of unrealistically high rainfall reduction.

Acknowledgements. Special thanks go to Lukas Neuhaus, Delon Wagner, Emil Blattmann, Johannes Bruckhoff, and Carsten Beinhoff for technical support and help building the roofing constructions. The work has been funded by the DFG Priority Program 1374 "Infrastructure-Biodiversity-Exploratories" (DFG-Ref no. WE4598/3-1, GE1090/11-1, and BR1698/16-1). We thank the managers of the three exploratories, Swen Renner, Sonja Gockel, Andreas Hemp, Martin Gorke and Simone Pfeiffer for their work in maintaining the plot and project infrastructure, and Markus Fischer, the late Elisabeth Kalko, Eduard Linsenmair, Dominik Hessenmöller, Jens Nieschulze, Daniel Prati, Ingo Schöning, François Buscot, Ernst-Detlef Schulze and Wolfgang W. Weisser for their role in setting up the Biodiversity Exploratories project. Field work permits were issued by the responsible state environmental offices of Baden-Württemberg, Thuringia, and Brandenburg (according to $\$ 72 \mathrm{BbgNatSchG).}$

Edited by: Y. Kuzyakov

\section{References}

Abramoff M., Magelhaes P. J., and Ram S. J.: Image processing with Image, J. Biophotonics Int. 11, 36-42, 2004.

Albert, K. R., Ro-Poulsen, H., Mikkelsen, T.N., Michelsen, A., Van Der Linden, L., and Beier, C.: Effects of elevated CO2, warming and drought episodes on plant carbon uptake in a temperate heath ecosystem are controlled by soil water status, Plant, Cell Environ., 34, 1207-1222, 2011.

Ampoorter E., Baeten L., Koricheva J., Vanhellemont M., and Verheyen K.: Do diverse overstoreys induce diverse understoreys? Lessons learnt from an experimental-observational platform in Finland, Forest Ecol. Manage., 318, 206-215, 2014.

Bahn, M., Reichstein, M., Dukes, J. S., Smith, M. D., and McDowell, N. G.: Climate-biosphere interactions in a more extreme world, New Phytol., 2002, 356-359, 2014
Baudis, M., Ellerbrock, R. H., Felsmann, K., Gessler, A., Gimbel, K., Kayler, Z., Puhlmann, H., Ulrich, A., Weiler, M., Welk, E., and Bruelheide, H.: Intraspecific differences in responses to rainshelter-induced drought and competition of Fagus sylvatica L. across Germany, Forest Ecol. Manage., 330, 283-293, 2014

Beier, C., Beierkuhnlein, C., Wohlgemuth, T., Penuelas, J., Emmett, B., Körner, C., de Boeck, H., Christensen, J. H., Leuzinger, S., Janssens, I. A., and Hansen, K.: Precipitation manipulation experiments - challenges and recommendations for the future, Ecol. Lett. 15, 899-911, 2012.

Birkhofer, K., Schoening, I., Alt, F., Herold, N., Klarner, B., Maraun, M., Marhan, S., Oelmann, Y., Wubet, T., Yurkov, A., Begerow, D., Berner, D., Buscot, F., Daniel, R., Diekoetter, T., Ehnes, R. B., Erdmann, G., Fischer, C., Foesel, B., Groh, J., Gutknecht, J., Kandeler, E., Lang, C., Lohaus, G., Meyer, A., Nacke, H., Naether, A., Overmann, J., Polle, A., Pollierer, M. M., Scheu, S., Schloter, M., Schulze, E.-D., Schulze, W., Weinert, J., Weisser, W. W., Wolters, V., and Schrumpf, M.: General Relationships between Abiotic Soil Properties and Soil Biota across Spatial Scales and Different Land-Use Types, PLoS ONE, 7, e43292, doi:10.1371/journal.pone.0043292, 2012.

Carminati, A., Schneider, C. L., Moradi, A. B., Zarebanadkouki, M., Vetterlein, D., Vogel, H.-J., Hildebrandt, A., Weller, U., Schüler, L., and Oswald, S. E.: How the Rhizosphere May Favor Water Availability to Roots, Vadose Zone J., 10, 988, doi:10.2136/vzj2010.0113, 2011.

Christensen, J. H. and Christensen, O. B.: A summary of the PRUDENCE model projections of changes in European climate by the end of this century, Clim. Change, 81, 7-30, 2007.

Cohen, Y., Fuchs, M., and Green, G. C.: Improvement of the heat pulse method for determining sap flow in trees, Plant, Cell Environ., 4391-397, 1981

da Costa, A. C. L., Galbraith, D., Almeida, S., Portela, B. T. T., da Costa, M., de Athaydes Silva Jr., J., Phillips, O. L., Metcalfe, D. B., Levy, P., and Meir, P.: Effct of $7 \mathrm{yr}$ of experimental drought on vegetation dynamics and biomass storage of an eastern Amazonian rainforest, New Phytol., 187, 579-591, 2010.

Dermody, O., Weltzin, J. F., Engel, E. C., Allen, P., and Norby, R. $\mathrm{J}$ : How elevated $\left[\mathrm{CO}_{2}\right]$, warming, and reduced precipitation interact to affect soil moisture and LAI in an old field ecosystem?, Plant Soil, 301, 255-266, 2007

English, N. B., Weltzin, J. F., Fravolini, A., Thomas, L., and Williams, D. G.,: The influence of soil texture and vegetation on soil moisture under rainout shelters in a semi-desert grassland, J. Arid Environ., 63, 324-343, 2005.

Fay, P. A. Carlisle, J. D., Knapp, A. K., Blair, J. M., and Collins, S. L.: Altering Rainfall Timing and Quantity in a Mesic Grassland Ecosystem: Design and Performance of Rainfall Manipulation Shelters, Ecosystems, 3, 308-319, 2000.

Fischer, M., Kalko, E. K. V., Linsenmair, K. E., Pfeiffer, S., Prati, D., Schulze, E.-D., and Weisser, W. W.: Exploratories for LargeScale and Long-Term Functional Biodiversity Research, LongTerm Ecological Research: Between Theory and Application, edited by: Muller, F., Baessler, C., Schubert, H., and Klotz, S., Springer, 233 Spring Street, New York, Ny 10013, United States, 429-443, 2010.

Gessler, A., Keitel, C., Nahm, M., and Rennenberg, H.: Water shortage affects the water and nitrogen balance in central European beech forests, Plant Biol., 6, 289-298, 2004. 
Gilliam, F. S.: The ecological significance of the herbaceous layer in temperate forest ecosystems, Bioscience, 57, 845-858, 2007

Glaser, B., Jentsch, A., Kreyling, J., and Beierkuhnlein, C.: Soil-moisture change caused by experimental extreme summer drought is similar to natural inter-annual variation in a loamy sand in Central Europe, J. Plant Nutrit. Soil Sci., 176, 27-34, 2013.

Gregory, P. J.: Roots, rhizosphere and soil: the route to a better understanding of soil science?, Europ. J. Soil Sci., 57, 2-12, 2006.

Hommel, R., Siegwolf, R., Saurer, M., Farquhar, G. D., Kayler, Z., Ferrio, J. P., and Gessler, A.: Drought response of mesophyll conductance in forest understory species - Impacts on water-use efficiency and interactions with leaf water movement, Physiologia Plantarum, doi:10.1111/ppl.12160, 2014.

Kopittke, G. R., Tietema, A., van Loon, E. E., and Asscheman, D.: Fourteen annually repeated droughts surpressed autotrophic soil respiration and resulted in an ecosystem change, Ecosystems, 17, 242-257, 2014.

Kreuzwieser, J. and Gessler, A.: Global climate change and tree nutrition: influence of water availiability, Tree Physiol., 30, 1221$1234,2010$.

Leuzinger, S., Luo, Y., Beier, C., Dieleman, W., Vicca, S., and Körner, C.: Do global change experiments overestimate impacts on terrestrial ecosystems?, Trends Ecol. Evolut., 26, 236-241. 2011.

Maracchi, G., Sirotenko, O., and Bindi, M.: Impacts of present and future climate variability on agriculture and forestry in the temperate regions: Europe, Clim. Change, 70, 117-135, 2005.

McDowell, N., Pockman, W. T., Allen, C. D., Breshears, D. D. Cobb, N., Kolb, T., Plaut, J., Sperry, J., West, A., Williams, D. G., and Yepez, E. A.: Mechanisms of plant survival and mortality during drought: why do some plants survive while others succumb to drought?, New Phytol., 178, 719-739, 2008.

Ozolincius, R., Stakenas, V., Varnagiryte-Kabasinskiene, I., and Buozyte, R.: Artificial drought in Scots pine stands: effects on soil, ground vegetation and tree condition, Ann. Botan. Fenn., 46, 299-307, 2009.

Parra, A., Ramirez, D. A., Resco, V., Velasco, A., and Moreno, J. M.: Modifying rainfall patterns in a mediterranean shrubland: system design, plant responses, and experimental burning, Int. J. Biometeorol., 56, 1033-1043, 2012.

Prudhomme, C., Giuntoli, I., Robinson, E. L., Clark, D. B., Arnell, N. W., Dankers, R., Fekete, B. M., Franssen, W., Gerten, D., Gosling, S. N., Hagemann, S., Hannah, D. M., Kim, H., Masaki, Y., Satoh, Y., Stacke, T., Wada, Y., and Wisser, D.: Hydrological drought in the 21st century, hotspots and uncertainties from a global multimodel experiment, Proc. Natl. Acad. Sci. USA, 111, 32627, doi:10.1073/pnas.1222473110, 2014
Rodriguez-Calcerra, J., Atkin, O. K., Robson, T. M., ZaragozaCastells, J., Gil, L., and Aranda, I.: Thermal acclimation of leaf dark respiration of beech seedlings experiencing summer drought in high and low light environments, Tree Physiol., 30, 214-224, 2009 .

Schaumann, G. E., Braun, B., Kirchner, D., Rotard, W., Szewzyk, U., and Grohmann, E.: Influence of biofilms on the water repellency of urban soil samples, Hydrol. Proc., 21, 2276-2284, 2007.

Schraml, C. and Rennenberg, H.: The different reactions of beech tree (Fagus sylvatica L.) ecotypes to drought stress, Forstw. Cbl., 121, 59-72, 2002.

Selsted, M. B., Linden, L., Ibrom, A., Michelsen, A., Larsen, K. S., Pedersen, J. K., Mikkelsen, T. N., Pilegaard, K., Beier, C., and Ambus, P.: Soil respiration is stimulated by elevated $\mathrm{CO} 2$ and reduced by summer drought: three years of measurements in a multifactor ecosystem manipulation experiment in a temperate heathland (CLIMAITE), Glob. Change Biol., 18, 1216-1230, 2012.

Seneviratne, S. I., Luethi, D., Litschi, M., and Schaer, C.: Landatmosphere coupling and climate change in Europe, Nature, 443, 205-209, 2006.

Spohn, M. and Rillig, M.C.: Temperature- and moisture-dependent soil water repellency induced by the basidiomycete Agaricus bisporus, Pedobiologia, 55, 59-61, 2012.

Tang, J., Mo, Y., Zhang, J., and Zhang, R.: Influence of biological aggregating agents associated with microbial population on soil aggregate stability, Appl. Soil Ecol., 47, 153-159, 2011.

Tschaplinski, T. J., Gebre, G. M., Shirshac, T. L.: Osmotic potential of several hardwood species as affected by manipulation of throughfall precipitation in an upland oak forest during a dry year, Tree Physiol. 18, 291-298, 1998.

Tisdall, J. M. and Oades, J. M.: Organic matter and water-stable aggregates in soils, J. Soil Sci., 33, 141-163, 1982.

Vicca, S. Gilgen, A. K., Camino serrano, M., Dreesen, F. E., Dukes, J. S., Estiarte, M., Grey, S. B., Guidolotti, G., Hoeppner, S. S., Leakey, A. D. B., Ogaya, R., Ort, D. R., Ostrogovic, M. Z., Rambal, S., Sardans, J., Schmitt, M., Siebers, M., van der Linden, L., van Straatten, O., and Granier, A.: Urgand need for a common metric to make precipitation manipulation experiments comperable, New Phytol., 195, 518-522, 2012

Wu, Z., Dijkstra, P., Koch, G. W., Peñuelas, J., and Hungate, B. A.: Responses of terrestrial ecosystems to temperature and precipitation change: a meta-analysis of experimental manipulation, Glob. Change Biol., 17, 927-942, 2011.

Yepez, E., Huxman, T., Ignace, D., English, N., Weltzin, J., Castellanos, A., and Williams, D.: Dynamics of transpiration and evaporation following a moisture pulse in semiarid grassland: A chamber-based isotope method for partitioning flux components, Agr. Forest Meteorol., 132, 359-376, 2005. 